\title{
Transcriptional profile of sweet orange in response to chitosan and salicylic acid
}

\author{
Danila Souza Oliveira Coqueiro 1,2, Alessandra Alves de Souza', Marco Aurélio Takita', Carolina Munari Rodrigues', \\ Luciano Takeshi Kishi ${ }^{3}$ and Marcos Antonio Machado ${ }^{1 *}$
}

\begin{abstract}
Background: Resistance inducers have been used in annual crops as an alternative for disease control. Wood perennial fruit trees, such as those of the citrus species, are candidates for treatment with resistance inducers, such as salicylic acid (SA) and chitosan (CHI). However, the involved mechanisms in resistance induced by elicitors in citrus are currently few known.

Results: In the present manuscript, we report information regarding the transcriptional changes observed in sweet orange in response to exogenous applications of SA and $\mathrm{CHI}$ using RNA-seq technology. More genes were induced by SA treatment than by $\mathrm{CHI}$ treatment. In total, 1,425 differentially expressed genes (DEGs) were identified following treatment with SA, including the important genes WRKY50, $P R 2$, and $P R 9$, which are known to participate in the salicylic acid signaling pathway, and genes involved in ethylene/Jasmonic acid biosynthesis (ACS12, AP2 domain-containing transcription factor, and OPR3). In addition, SA treatment promoted the induction of a subset of genes involved in several metabolic processes, such as redox states and secondary metabolism, which are associated with biotic stress. For $\mathrm{CHI}$ treatment, there were 640 DEGs, many of them involved in secondary metabolism. For both SA and CHI treatments, the auxin pathway genes were repressed, but SA treatment promoted induction in the ethylene and jasmonate acid pathway genes, in addition to repressing the abscisic acid pathway genes. Chitosan treatment altered some hormone metabolism pathways. The DEGs were validated by quantitative Real-Time PCR (qRT-PCR), and the results were consistent with the RNA-seq data, with a high correlation between the two analyses.
\end{abstract}

Conclusions: We expanded the available information regarding induced defense by elicitors in a species of Citrus that is susceptible to various diseases and identified the molecular mechanisms by which this defense might be mediated.

Keywords: Citrus, Gene expression, Metabolic pathway, RNA-seq

\section{Background}

Citrus is one of the most important crops around the world. Brazil is currently the largest producer of sweet oranges and is the largest producer and exporter of freezer concentrate and not-from-concentrate orange juice [1]. However, one of the limiting factors that threatens the growth and productivity of citrus production are citrus diseases. The integrated management of plant (IMP) diseases advocates alternate technologies, such as biological control and genetic resistance, to reduce the deleterious effects of pathogens. One strategy that may contribute to disease reduction is the use of

\footnotetext{
*Correspondence: marcos@centrodecitricultura.br

'Laboratório de Biotecnologia, Centro de Citricultura Sylvio Moreira, IAC

Cordeirópolis, São Paulo, Brasil

Full list of author information is available at the end of the article
}

elicitors to improve the natural resistance of the plant. Among the compounds that have been used to control pathogens are salicylic acid (SA) and chitosan (CHI).

SA is a phenolic compound produced by plants, and its biosynthesis and signaling pathways have been well characterized, demonstrating its important role as a signal involved in the plant defense against pathogens [2]. The biosynthesis of SA may culminate in the expression of resistance genes that promote systemic acquired resistance (SAR). During infection, SA accumulates at the site of pathogen penetration, acting in the hypersensitivity reaction, and is also distributed to other parts of the plants as a mobile signal, as methyl salicylate, to induce a range of defense responses [3]. Many plants are not able to deploy these mechanisms effectively. Studies on the exogenous application of SA in plants have revealed 
that it may induce systemic resistance and promote the accumulation of pathogenesis-related (PR) proteins [4]. The effectiveness of SA treatment has been verified against diseases caused by virus [5], fungi [6,7], and bacteria $[8,9]$. The exogenous application of SA has been shown to induce PR1 mRNA and to reduce the systemic multiplication of the Alfalfa mosaic virus (A1MV) [5]. The potential for the exogenous application of SA to increase PR protein expression in bean plants and to reduce local lesions caused by A1MV was also demonstrated [5]. SA treatment promoted the resistance of asparagus against Fusarium oxysporum f. sp. asparagi, with increases in the levels of peroxidases, phenylalanine ammonia-lyase, and lignifications [6]. Similar results were obtained in tomato plants, where the application of SA to the roots reduced vascular browning caused by $F$. oxysporum $f$. sp. lycopersici and increased the levels of peroxidases, phenylalanine ammonia-lyase activities and the endogenous accumulation of free SA, showing that the root system might assimilate and distribute SA throughout the plant [7]. SA treatment was also effective in inducing several PR proteins in grapevine leaves [10]. In addition to demonstrating the effectiveness of SA applications against virus and fungi, studies have reported the effects of exogenous applications of SA for the control of bacterial diseases. There was an increase in the resistance of tobacco against Erwinia carotovora following SA treatment, which promoted reductions in disease symptoms and bacterial multiplication [11]. A recent study demonstrated the potential for SA treatment to attenuate the symptoms of citrus canker in sweet orange [Citrus sinensis (L.) Osbeck] by measuring the enzyme activities of phenylalanine ammonia-lyase and $\beta$-1,3-glucanase, as well as the mRNA levels of $\mathrm{Cs} C H I$ and CsPR4 [12].

Chitosan, a $\beta-1,4-$ linked glucosamine, is a deacetylated derivative of chitin and has a double effect: it is antimicrobial and it activates several plant defense mechanisms during host-pathogen interactions, such as the hypersensitivity reaction, callose deposition, lignification, synthesis of abscisic acid, phytoalexins, and pathogenesis-related proteins [13-17]. In grapevine, $\mathrm{CHI}$ treatment was effective against powdery mildew, reducing disease severity and increasing the polyphenol content [18]. A recent study showed that $\mathrm{CHI}$ can act on the phenylpropanoid pathway, increasing the levels of phenolic compounds in tomato plants and contributing to the reduction of bacterial spots [19]. In fruit trees, much of the research conducted on $\mathrm{CHI}$ treatments has been focused on post-harvest treatment, due to the ability of this polysaccharide to form a semi-permeable biofilm that modifies the atmosphere and reduces losses due to perspiration and dehydration, thus increasing the shelf life of fruits. Furthermore, $\mathrm{CHI}$ treatment may lead to the induction of resistance in fruits $[20,21]$.
Previously, researchers evaluated the induction of resistance in plants by analyzing individual mechanisms involved in the stress response. However, these strategies contribute little to the comprehension of the defenserelated mechanisms promoted by elicitors of resistance. Large-scale studies of gene expression have been increasingly conducted to assess the effects of elicitors on plant metabolism. The transcriptional profile of sorghum following exogenous applications of SA showed the induction of several defense genes, such as numerous PR genes and members of the phenylpropanoid and jasmonic acid (JA) pathway, showing patterns of synergistic effects between SA and JA, as well as mutual antagonism for the regulation of some genes [22]. Studies conducted by RNA-seq to describe the transcriptome in Taxus chinensis in response to the exogenous application of methyl jasmonate (MeJA) revealed thein duction of JA biosynthesis/JA signaling pathway/defense responses [23]. For CHI-treated Arabidopsis thaliana that was challenged with Botrytis cinerea, the transcriptome profile showed that the polysaccharide was able to induce camalexin biosynthesis genes through of the CERK1-independent pathway [24]. To the best of our knowledge, there are no previous studies showing the effects of CHI treatment in sweet orange. Although studies examining the exogenous application of SA on citrus are available, these studies lack the information regarding the changes in the general profile that are caused by the elicitor. To provide a large-scale study of gene expression in citrus treated with SA and CHI, and considering the important role, these elicitors have played in inducing defense mechanisms in several species, in the present study we aimed to evaluate the changes in the transcript pattern in sweet orange plants induced by these elicitors. The Illumina platform has been widely used to generate transcriptional profiles though RNA-seq, providing greater accuracy in measuring the levels of transcript. Using this method, we observed important changes mediated by elicitors in the defense response of sweet orange.

\section{Results and discussion}

In a preliminary experiment, leaves of sweet orange cv. Pera were sprayed with SA and CHI at different concentrations to test transcriptional induction of key genes of the SA and ethylene response pathway. Leaves were chosen because the most important Citrus diseases affect the aerial part of the plants and none of the treatments was shown to be phytotoxic. In addition, the results revealed that the best concentrations for $\mathrm{CHI}$ and SA were $4 \mathrm{mg} / \mathrm{mL}$ and $2.5 \mathrm{mM}$, respectively. The interval of 48 hours was the most appropriate for testing the response to $\mathrm{CHI}$ while for SA it was 24 hours (data not shown). These conditions were used for the RNAseq experiment setup. 


\section{Transcriptome profiling}

To contribute to the understanding of how SA and CHItreatments promote changes in transcript expression in sweet orange, transcriptional profiles of leaf samples treated with elicitors were generated using RNA-seq. Total RNA was extracted from elicitor-treated sweet orange plants and mock-treated plants (ethanol solution $10 \%$ or $\mathrm{HCl} 0.05 \mathrm{~N}, \mathrm{pH} 5.6$ for SA and chitosan, respectively), and then four cDNA libraries were created for sequencing with Illumina technology.

Between 11 and 15 million 31-nt paired end were generated from leaves that received different treatments (see Additional file 1: Table S1 and Additional file 2: Table S2). The Table 1 provides information about sequencing quality. The reads were aligned with the Citrus clementina reference genome and comparisons were made between SA- and E-treated plants (mock) and between CHI- and $\mathrm{H}$-treated plants (mock) (see Additional file 1: Table S1 and Additional file 2: Table S2). The numbers of transcripts with significantly altered expression levels $(P \leq 0.05)$ following treatment with elicitors, based on the Cuffdiff analysis, are shown in Table 1. Compared to controls, more downregulated genes were identified than up-regulated genes in plants treated with elicitors. Among the genes significantly induced by the treatments, 350 were unique to SA-treated plants, and 194 were unique to $\mathrm{CHI}$-treated plants. Among the genes that were significantly repressed, 1,073 were unique to SA-treated plants, and 444 were unique to $\mathrm{CHI}$ treated plants (Figure 1). Only two genes were coregulated by $\mathrm{SA}$ and $\mathrm{CHI}$ treatments (encoding disease resistance family protein/leucine rich repeats (LRR) family protein, and hypothetical protein), and these genes were corepressed. Between the two treatments, SA treatment altered the mRNA levels of a substantially greater number of genes compared with CHI treatment (Figure 1).

All of the differentially up- and down-regulated genes were functionally categorized based on Gene Ontology (GO), in biological process, cellular component, and molecular function (level 2) (Table 2), and visualizations of the functional groups that were significantly altered by the treatments were generated by PageMan [25] and MapMan 3.5.1R2 [26] software.
The differentially expressed genes were distributed into 10 biological processes, five cellular components and nine molecular functions. Within each category, the greatest number of $\mathrm{GO}$ annotated genes were associated with metabolic processes $(28.3 \%$ for both $\mathrm{SA}$ and $\mathrm{CHI}$ treatments), cellular processes $(27 \%$ for SA treatment and $28.9 \%$ for CHI treatment), cell (51.4\% for SA treatment and $52.1 \%$ for $\mathrm{CHI}$ treatment), and binding (42.6\% for SA treatment and $45.7 \%$ for $\mathrm{CHI}$ treatment) (Table 2).

For SA treatment, nearly $12 \%$ of the altered genes were considered to be genes that change expression in response to stimulus, and for $\mathrm{CHI}$ treatment that number was nearly $8 \%$ (Table 2). The transcripts most strongly up-regulated by SA treatment were those that encoded peroxidase superfamily proteins, which are involved in the response to oxidative stress during the defense response and the deposition of lignin, 2oxoglutarate (2OG) and Fe(II)-dependent oxygenase superfamily proteins that are involved in the biosynthetic process of flavonoids, and $\beta$-1,3-glucanase, which has antimicrobial properties (see Additional file 3: Table S3, Additional file 4: Table S4-1, Additional file 5: Table S4-2). For CHI treatment, the most strongly up-regulated transcripts were those that encodes members of the tetratricopeptide repeat-like superfamily, the glycosyltransferase family, and the 2OG and Fe(II)-dependent oxygenase superfamily (see Additional file 6: Table S5, Additional file 7: Table S6-1, and Additional file 8: Table S6-2).

\section{Modulated metabolic process induced by exogenous SA and $\mathrm{CHI}$}

Many studies have shown that applications of exogenous $\mathrm{SA}$ and $\mathrm{CHI}$ increase the defense response in several plants [5-21]. SA is required for SAR and plays an important role in defense signaling. In a study performed in Citrus sinensis Osbeck it was demonstrated that SA treatment was able to enhance resistance against Xanthomonas axonopodis pv. citri elevating the activities of phenylalanine ammonia-lyase and glucanase, and the mRNA levels of CsCHI and CsPR4A [12]. However, studies of the large-scale transcriptional responses

Table 1 RNA-seq raw data and number of differentially expressed transcripts

\begin{tabular}{lllll}
\hline Treatment & Number of reads & CG (\%) & Q (20\%) & Transcripts with changed expression $^{\ddagger}$ \\
\hline $\mathrm{CHI}$ & $11,691,216$ & 43.39 & 92.68 & 640 \\
$\mathrm{H}^{*}$ & $13,253,654$ & 43.36 & 92.56 & - \\
$\mathrm{SA}$ & $14,833,464$ & 43.35 & 93.92 & 1,425 \\
$\mathrm{E}^{*}$ & $12,279,260$ & 43.64 & 92.34 & - \\
\hline
\end{tabular}

* $\mathrm{H}$ and $\mathrm{E}$ represent the controls for $\mathrm{CHI}$ and $\mathrm{SA}$, respectively.

${ }^{\dagger} \mathrm{CG}$ represents the quantity of $\mathrm{CG}$ bases in the sequences.

${ }^{\ddagger}$ Corresponds to sequences with Phred quality $>20$, which was higher than $92 \%$ for all RNA-seq libraries.

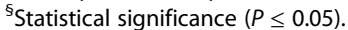

All transcripts (up- and down-regulated) were obtained by RNA-seq after treatment with elicitors when compared to controls, according to Cuffdiff analysis. 


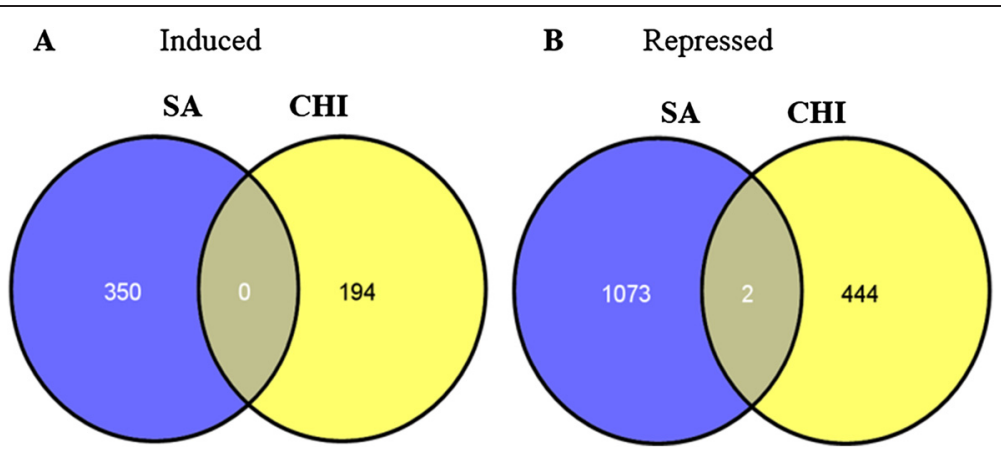

Figure 1 Venn diagrams showing the number of genes with significantly altered expression levels ( $P \leq 0.05$ and $\leq 1$ fold change). Non-overlapping numbers represent the number of genes unique to a particular treatment (CHI or SA). Overlapping numbers represent the number of mutual genes between treatments. Panel $\mathbf{A}$ represents the induced transcripts and Panel $\mathbf{B}$ the repressed ones.

Table 2 Functional categorization of up- and down-regulated genes after treatments with SA and CHI

\begin{tabular}{|c|c|c|c|c|c|}
\hline \multirow[t]{2}{*}{ Categories* } & \multirow[t]{2}{*}{ Name } & \multicolumn{4}{|c|}{ Number of transcripts } \\
\hline & & $\mathrm{UP}_{\mathrm{SA}}$ & DOWN $_{\text {SA }}$ & $\mathrm{UP}_{\mathrm{CHI}}$ & $\mathrm{DOWN}_{\mathrm{CH}}$ \\
\hline \multirow[t]{11}{*}{ Biological process } & Metabolic process & 179 & 122 & 81 & 221 \\
\hline & Cellular process & 161 & 137 & 79 & 229 \\
\hline & Response to stimulus & 68 & 59 & 20 & 70 \\
\hline & Biological regulation & 47 & 49 & 28 & 93 \\
\hline & Localization & 42 & 30 & 16 & 47 \\
\hline & Multicellular organismal process & 25 & 20 & 8 & 44 \\
\hline & Developmental process & 23 & 22 & 8 & 44 \\
\hline & Multi-organism process & 17 & 7 & 4 & 13 \\
\hline & Cellular component organization & 15 & 16 & 8 & 25 \\
\hline & Signaling & 9 & 17 & 10 & 18 \\
\hline & Total annotations & 586 & 479 & 262 & 804 \\
\hline \multirow[t]{6}{*}{ Cellular component } & Cell & 196 & 142 & 102 & 283 \\
\hline & Organelle & 140 & 98 & 73 & 197 \\
\hline & Macromolecular complex & 42 & 12 & 22 & 40 \\
\hline & Membrane-enclosed lumen & 9 & 4 & 4 & 11 \\
\hline & Extracellular region & 8 & 3 & 3 & 4 \\
\hline & Total annotations & 395 & 259 & 204 & 535 \\
\hline \multirow[t]{10}{*}{ Molecular function } & Binding & 157 & 140 & 77 & 281 \\
\hline & Catalytic activity & 149 & 123 & 74 & 217 \\
\hline & Transporter activity & 25 & 25 & 7 & 33 \\
\hline & Electron carrier activity & 15 & 3 & 15 & 5 \\
\hline & Structural molecule activity & 14 & 2 & 7 & 4 \\
\hline & Molecular transducer activity & 11 & 9 & 7 & 17 \\
\hline & Enzyme regulator activity & 8 & 6 & 3 & 2 \\
\hline & Antioxidant activity & 5 & 0 & 2 & 3 \\
\hline & Transcription regulator activity & 1 & 5 & 6 & 23 \\
\hline & Total annotations & 385 & 313 & 198 & 585 \\
\hline
\end{tabular}


promoted by SA and $\mathrm{CHI}$ treatments have not yet been reported in citrus. Our results provided a broader vision of the mechanisms involved in response induced by SA treatment and were consistent with the mechanisms discussed in previous studies, demonstrating that exogenous SA application increased the expression levels of genes involved in the defense response. However, $\mathrm{CHI}$ treatment did not promote considerable changes in the expression levels of genes involved in plant defense metabolism.

Genes with putative roles in photosynthesis, cell wall synthesis/degradation/modification, hormone metabolism, the regulation of oxidative states, and transcriptional regulation showed distinctive patterns of regulation, as shown in Figure 2, which was obtained using PageMan software.

Several subsets of genes encoding receptor-like kinases, signaling proteins, transcriptional factors, oxidative stress response elements, secondary metabolism factors, and phytohormone-responsive genes were identified (Figure 3). Notably, a greater number of genes were modulated by SA treatment than by $\mathrm{CHI}$ treatment in all of the identified pathways. The functions of the genes described below are based on homology to genes of known functions from other organisms, primarily $A$. thaliana, with the help of MapMan software.

\section{Genes associated with defense signaling/activation and redox state}

A sequence of molecular events leads to the establishment of plant defense mechanisms, and the first step of this sequence is the recognition of the elicitor molecule by a specific receptor. Our results have shown that several receptor-like kinases were observed among the differentially expressed genes, with a greater number of genes that contain a LRR sequence being identified in SA-treated plans than in CHI-treated plants. Of these LRR containing genes, only one was considered upregulated in SA-treated plants, where as two were considered up-regulated in $\mathrm{CHI}$-treated plants. One member of the receptor-like kinase (RLK) family was induced only by SA treatment, while the receptor kinase associated to extensin, which participate of the primary cell wall of plants, was repressed in both treatment groups (see Additional file 3: Table S3 and Additional file 6: Table S5). The phosphoinositide-specific phospholipase $\mathrm{C}$ (PLC) pathway may respond to hormones or pathogen elicitors by releasing cytosolic $\mathrm{Ca}^{2+}[27]$. The gene encoding the plasma membrane protein PLC4 was also induced by both SA and $\mathrm{CHI}$ treatments.

Our results suggest that in sweet orange exogenous SA might be activating RLK receptors. In A. thaliana, it

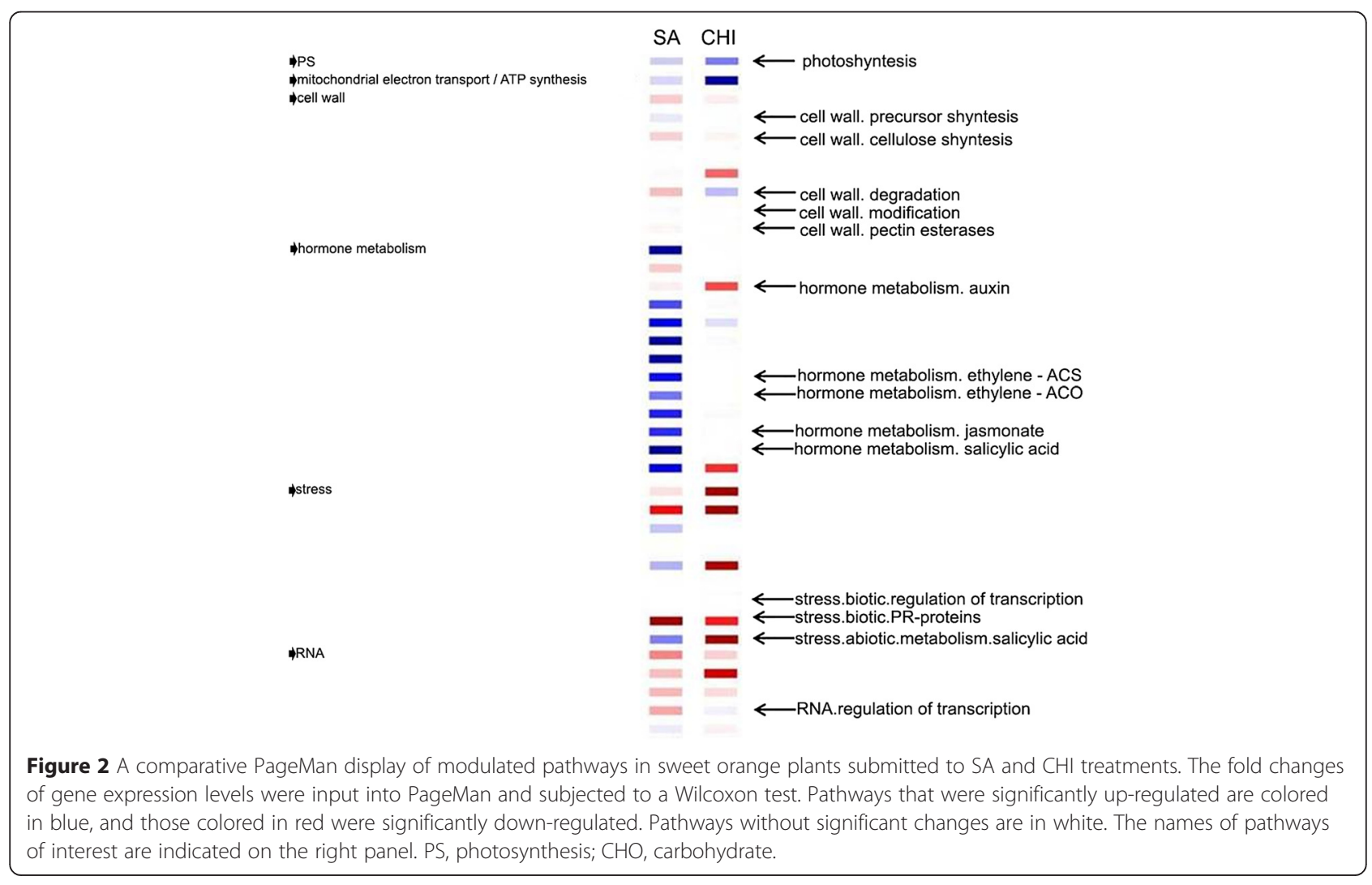




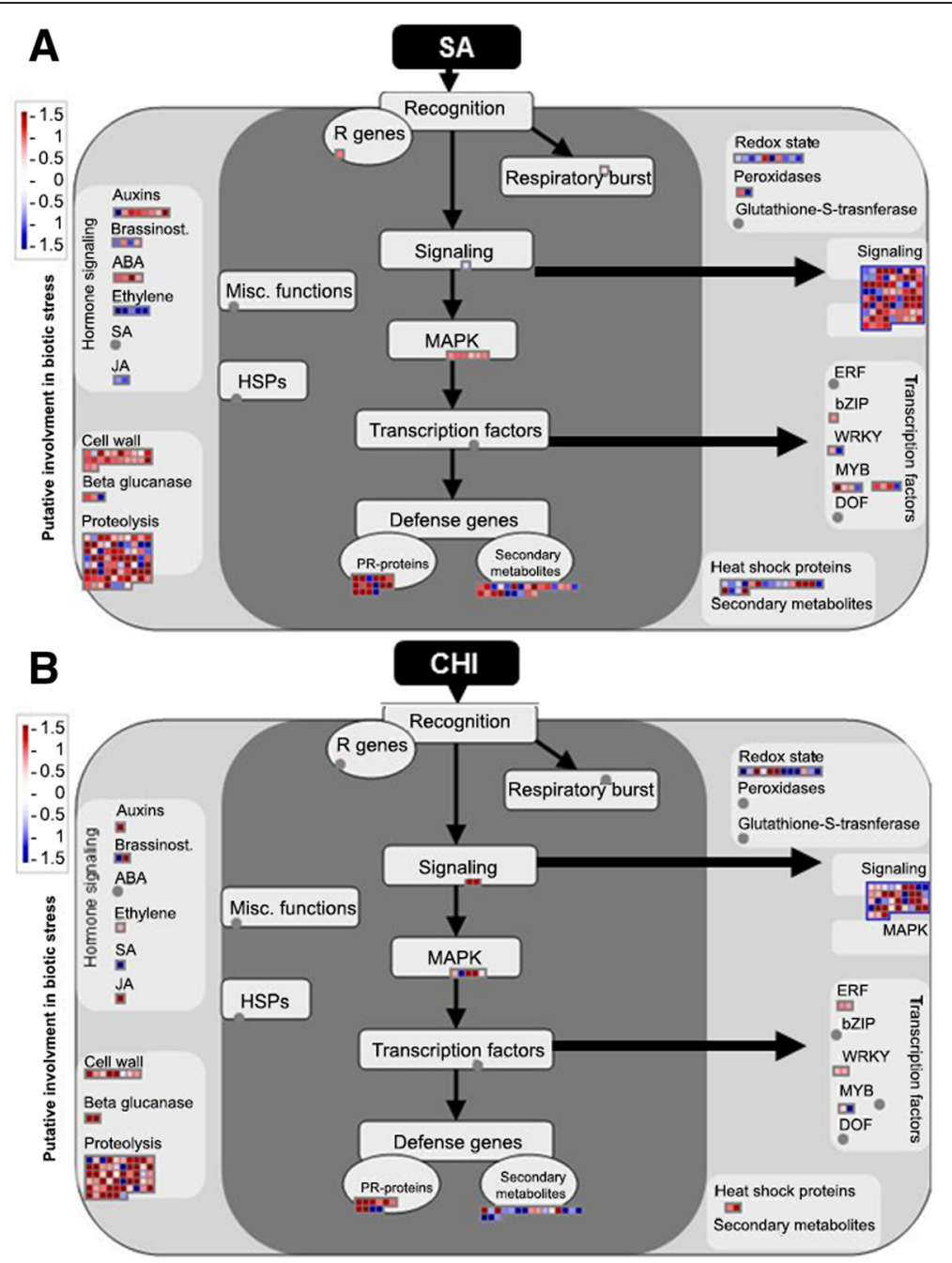

Figure 3 Differentially expressed transcripts related to stress responses. Treatment-modulated stress responses were evaluated in SA-treated plants (A) and CHI-treated plants (B). The fold change of gene expression levels were analyzed using MapMan. Small red and blue squares represent up- and down-regulated genes, respectively.

was observed that the exogenous application of SA increased the expression levels of $R L K$ genes, which exhibit a TTGAC sequence in their promoter regions that appear to be related to plant defense genes [28]. Thus, it is possible that exogenous SA might be recognized by RLK family members and might be able to increase the expression levels of various RLKs in citrus. The exact $\mathrm{CHI}$ recognition mechanisms in plants are not completely understood. Studies have suggested that $\mathrm{CHI}$ can be recognized by chitin receptors, such as CERK [29] however, in A. thaliana, it was observed that the perception of CHI occurred through a CERK1independent pathway [24]. In our results, the CERK gene was not represented in the profile of CHI-treated plants, suggesting that the $\mathrm{CHI}$ is recognized by CERK independent mechanisms.
Another signaling factor that appeared to be involved in SA treatment but was not observed in $\mathrm{CHI}$ treatment was the repression of the GLB1 gene (GLNB1-like protein), which is responsible for encoding a haemoglobin that oxidizes nitric oxide (NO) [30]. The suppression of GLB1 suggests that SA treatment can favor the accumulation of NO in citrus, as has been shown in A. thaliana [31]. Just as studies have demonstrated that SA produces $\mathrm{NO}$, it is also possible that NO stimulates SA accumulation [32,33]. Both signaling molecules, SA and NO, are well known to play important roles in the activation of plant defense after elicitation. However, the interrelationship between these two signaling molecules and their pathways is not understood. It is likely that SA and NO promote the hypersensitive response and pathogen death [34]. 
Because elicitors are recognized and accumulate in cells, they may trigger diverse processes, such as redox regulation. Oxidative stress occurs when there are changes in environmental conditions, causing the cell to produce reactive oxygen species (ROS), which result in the oxidation of cellular components, alter metabolic activities and affect organelle integrity. Thus, balancing these ROS through the activation of ROS responsive regulatory genes is required [35]. Several proteins play a critical role in redox in plants, including thioredoxins, superoxide dismutase, and glutaredoxin. Thioredoxins were induced by SA and $\mathrm{CHI}$ treatments. These proteins may participate in the conversion of $N R P 1$ (SA-induced nonexpresser of $P R$ genes 1) to a monomer when the plant is elicited, by a pathogen or by SA treatment [36]. CSD2 (copper/zinc superoxide dismutase 2 ), which was induced by both treatments as determined by RNA-seq and by qRT-PCR (Tables 3 and 4), may promote the dismutation of superoxide radicals $\left(\mathrm{O}_{2}^{-}\right)$in $\mathrm{H}_{2} \mathrm{O}_{2}$, which is part of the programmed cell death of plant cells and has been correlated with disease resistance [37]. The enhanced expression of superoxide dismutase by $\mathrm{SA}$ and $\mathrm{CHI}$ treatments has been reported in A. thaliana. Kliebenstein et al. [38] have shown that treatment with the SA analogs

Table 3 Defense-genes up- and down-regulated in sweet orange in response to SA-treatment $(P<0.01)$

\begin{tabular}{|c|c|c|c|}
\hline \multicolumn{4}{|l|}{$\overline{S A}$} \\
\hline Gene ID & Gene name/function & RNA-seq ${ }^{*}$ & qRT-PCR \\
\hline AT1G19220 & $\begin{array}{l}\text { ARF19/ auxin response } \\
\text { factor } 19\end{array}$ & -2.67 & -1.39 \\
\hline AT3G12500 & 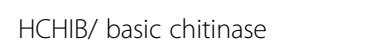 & -2.13 & $N A^{\ddagger}$ \\
\hline AT5G14420 & RGLG2/ RING domain ligase 2 & -1.89 & -1.92 \\
\hline AT3G62980 & $\begin{array}{l}\text { TIR1/ F-box/RNI-like } \\
\text { superfamily protein }\end{array}$ & -1.19 & -1.17 \\
\hline AT1G75580 & $\begin{array}{l}\text { SAUR-like auxin-responsive } \\
\text { protein family }\end{array}$ & -1.12 & -1.85 \\
\hline AT5G17820 & Peroxidase superfamily protein & 3.19 & 1.09 \\
\hline AT2G28190 & $\begin{array}{l}\text { CSD2/copper/zinc superoxide } \\
\text { dismutase } 2\end{array}$ & 2.27 & 1.04 \\
\hline AT3G57260 & BGL2/beta-1,3-glucanase 2 & 2.06 & 1.14 \\
\hline AT4G10490 & $\begin{array}{l}\text { 2-oxoglutarate (2OG) and } \\
\text { Fe(II)-dependent oxygenase } \\
\text { superfamily protein }\end{array}$ & 1.80 & 3.07 \\
\hline AT2G32440 & $\begin{array}{l}\text { ACS12/ 1-aminocyclopropane-1- } \\
\text { carboxylate synthase }\end{array}$ & 1.54 & NA \\
\hline AT5G26170 & $\begin{array}{l}\text { WRKY } 50 / \text { WRKY DNA-binding } \\
\text { protein } 50\end{array}$ & 1.31 & 1.42 \\
\hline AT5G23960 & TPS21/terpene synthase 21 & 1.05 & NA \\
\hline AT2G06050 & $\begin{array}{l}\text { OPR3/12-oxophytodienoate } \\
\text { reductase } 3\end{array}$ & 1.03 & NA \\
\hline AT1G05010 & $\begin{array}{l}\text { 1-aminocyclopropane-1- } \\
\text { carboxylate oxidase }\end{array}$ & 0.9 & 0.85 \\
\hline
\end{tabular}

Table 4 Defense-genes up- and down-regulated in sweet orange in response to $\mathrm{CHI}$-treatment $(P<0.01)$

CHI

\begin{tabular}{|c|c|c|c|}
\hline Gene ID & Gene name/function & RNA-seq $^{\dagger}$ & $\mathrm{qRT}^{-P C R^{\dagger}}$ \\
\hline AT5G60450 & ARF4/auxin response factor 4 & $-227.07^{* *}$ & $N A^{\ddagger}$ \\
\hline AT3G12500 & $\mathrm{HCHIB/basic} \mathrm{chitinase}$ & -226.22 & NA \\
\hline AT5G62000 & ARF2/auxin response factor 2 & -182.94 & -1.81 \\
\hline AT3G61415 & $\begin{array}{l}\text { EBF1 - protein binding/ubiquitin- } \\
\text { protein ligase }\end{array}$ & $-134,34$ & $-1,36$ \\
\hline AT2G25490 & $\begin{array}{l}\text { SK21/SKP1-like 21-SCF } \\
\text { ubiquitin ligase complex }\end{array}$ & -135.59 & -2.56 \\
\hline AT5G17420 & Cellulose synthase & -160.14 & -1.67 \\
\hline AT2G02560 & $\begin{array}{l}\text { CAND1/cullin-associated and } \\
\text { neddylation dissociated }\end{array}$ & -198.86 & NA \\
\hline AT5G49330 & MYB111/myb domain protein 111 & 175.1 & NA \\
\hline AT3G50740 & UDP-glucosyltransferase 72 E1 & 158.32 & NA \\
\hline AT3G11480 & $\begin{array}{l}\text { BSMT1/S-adenosyl-L-methionine- } \\
\text { dependent methyltransferases } \\
\text { superfamily protein }\end{array}$ & 158.09 & NA \\
\hline AT4G13400 & $\begin{array}{l}\text { 2-oxoglutarate (2OG) and } \\
\text { Fe(II)-dependent oxygenase } \\
\text { superfamily protein }\end{array}$ & 153.90 & 1.31 \\
\hline AT4G34050 & $\begin{array}{l}\text { CCOAOMT1/S-adenosyl-L- } \\
\text { methionine-dependent } \\
\text { methyltransferases superfamily } \\
\text { protein }\end{array}$ & 111.50 & NA \\
\hline AT2G28190 & $\begin{array}{l}\text { CSD2/copper/zinc superoxide } \\
\text { dismutase } 2\end{array}$ & 104.85 & 1.30 \\
\hline
\end{tabular}

2,6-dichloroisonicotinic acid and benzothiadiazole Smethylester (BTH) induced two CuZnSOD proteins, which is consistent with the differential expression of CSD2 in SA-treated plants observed in our results. Similarly, the protective effect of $\mathrm{CHI}$ against brown rot in peaches was associated with the induction of superoxide dismutase activity [39]. Therefore, SA and CHI appear to act in plant protection by contributing to programmed cell death during the important event of disease resistance.

\section{Genes associated with the cell wall and secondary metabolism}

Under the conditions used in this study, most of the genes associated with cell wall related-pathways were repressed by the treatments (e.g., any cellulose synthase, expansin, extensin, and UDP-arabinose 4-epimerase see Additional file 4, Additional file 5 and Additional file 6), with more genes being represented in the profile for SAtreated plants. Expansin is involved in cell wall modification. This enzyme is required for wall relaxation during plant cell enlargement [40]. Proteins that loosen the cell wall play key roles in plant growth, however, this process 
may also make the plant vulnerable to attack by pathogens [41]. Thus, these data support the idea that expansin is negatively regulated by SA treatment. The auxin hormone, which has been implicated in disease susceptibility, induces the expression of expansins [41]. The suppression of auxin signaling by microRNA in $A$. thaliana resulted in the restriction of Pseudomonas syringae growth, indicating that the repression of auxin signaling is part of the plantinduced immune response [42]. Additionally, A. thaliana treated with the SA analog BTH showed the global repression of auxin-related genes, including the TIR1 receptor, indicating that the inhibition of auxin responses is a part of the SA-mediated disease-resistance mechanism [43]. We have shown that the sweet orange response to SA treatment appears to be functionally similar to that observed in A. thaliana. The factor that corroborates our results with those reported in previous studies is that expansins are induced by auxin, and this pathway was repressed in the present study. Other components of the auxin pathway were repressed and are described below. Among the few genes involved in cell wall metabolism with altered expression in the CHI treatment, genes involved in cellulose synthesis (e.g. cellulose synthase) were repressed, which was confirmed by qRT-PCR (Table 4).

It is well known that the treatment of plants with elicitors promotes the accumulation of defensive secondary metabolites. RNA-seq analysis showed that the expression levels of genes encoding enzymes associated with lignin synthesis, flavonoids, chalcones, and isoprenoid were altered in response to $\mathrm{SA}$ and/or $\mathrm{CHI}$ treatment (see Additional file 3: Table S3 and Additional file 6: Table S5). We observed that more than $60 \%$ of the differentially expressed genes in this group were repressed by treatments, including anthocyanins, chalcones, and 4coumaroyl-CoA synthase. However, the 2OG-Fe(II) oxygenase family protein was induced by both $\mathrm{SA}$ and $\mathrm{CHI}$ treatments, which was confirmed by qRT-PCR (Tables 3 and 4). In addition, the genes DMR6 (downy mildew resistant 6) and terpene synthase were observed to be induced by SA treatment. For $\mathrm{CHI}$ treatment, the induction of caffeoyl-CoA 3-O-methyltransferase, coniferyl-alcohol glucosyltransferase, and flavonoid 3'-monooxygenase was observed. The 2OG-Fe (II) oxygenase protein uses a dioxygen molecule to catalyze the 2OG and Fe (II)dependent oxidation of an organic substrate. In plants, the 2OG-Fe (II) oxygenase protein participates in the synthesis of diverse compounds, such as flavones. ACC oxidase (1-aminocyclopropane-1-carboxylate oxidase), which is involved in the biosynthesis of ethylene (ET) and was represented in the profile of SA-treated plants, belongs to this family [44]. DMR6 is also a member of the 2OG-Fe(II) oxygenase superfamily of oxidoreductases and has been considered an enzyme that is activated during various defense responses, which can be activated by pathogen stimulation or can be chemically induced. Van Damme et al. [45] analyzed several dmr6 mutants in A. thaliana and observed that DMR6 expression was sensitive to SA analogous. Interestingly, DMR6 was observed to be induced to higher levels during incompatible interactions than during compatible interactions. During incompatible interactions, the induction of genes dependent on SA is observed. Therefore, the authors suggest that DMR6 expression can be considered to be SAR-induced. Our results also indicated the participation of this gene in response to SA treatment in sweet orange.

A gene that is potentially involved with terpenoids was also observed to be regulated by treatments and is involved in secondary metabolism. The terpene synthases, which were induced by SA treatment but not by $\mathrm{CHI}$ treatment, are involved in the synthesis of various terpene molecules, which may serve as plant defenses against herbivores and pathogens [46-48]. However, we observed that $\mathrm{CHI}$ treatment induced important genes involved in phenylpropanoids metabolism, such as the caffeoyl CoA O-methyltransferases (see Additional file 6: Table S5, Additional file 7: Table S6-1, and Additional file 8: Table S6-2), which have been implicated in lignin biosynthesis and were not represented in the profile of SA-treated plants. The participation of $\mathrm{CHI}$ in phenylpropanoid metabolism has also been observed in tomato plants [19].

\section{Transcriptional factors and hormone metabolism}

Transcriptional factors were more strongly represented in the profile of SA-treated plants than in CHI-treated plants. A total of 106 regulated transcription factors were identified in SA-treated plants, and 59 were identified in CHI-treated plants (Figure 4A), including members of the WRKY, ARF, MYB, bHLH, bZIP, and AP2/ERF families (Additional file 6: Table S5). Most of these transcripts were down-regulated in both treatments (Figure 4A). Both treatments promoted the repression of ARF members involved in the response to auxin, which was confirmed by qRT-PCR (Tables 3 and 4). TIR1 (transport inhibitor response 1) was also repressed by SA treatment, which was also confirmed by qRT-PCR (Table 3). WRKY factors, which are known to be involved in biotic stress and to participate in defense responses, showed increased expression levels in SA-treated plants, with WRKY50 being upregulated, which was confirmed by qRT-PCR; however, WRKY2 and WRKY4 were repressed in CHI-treated plants. Unsurprisingly, SA treatment has the potential to induce the transcription factors in the WRKY family [49] (Figure 3A). The WRKY proteins form a large family of transcription factors that bind w-box elements and have the potential to differentially regulate the expression of a variety of target genes [50]. The WRKY family members appear to play regulatory roles in responses against biotic 


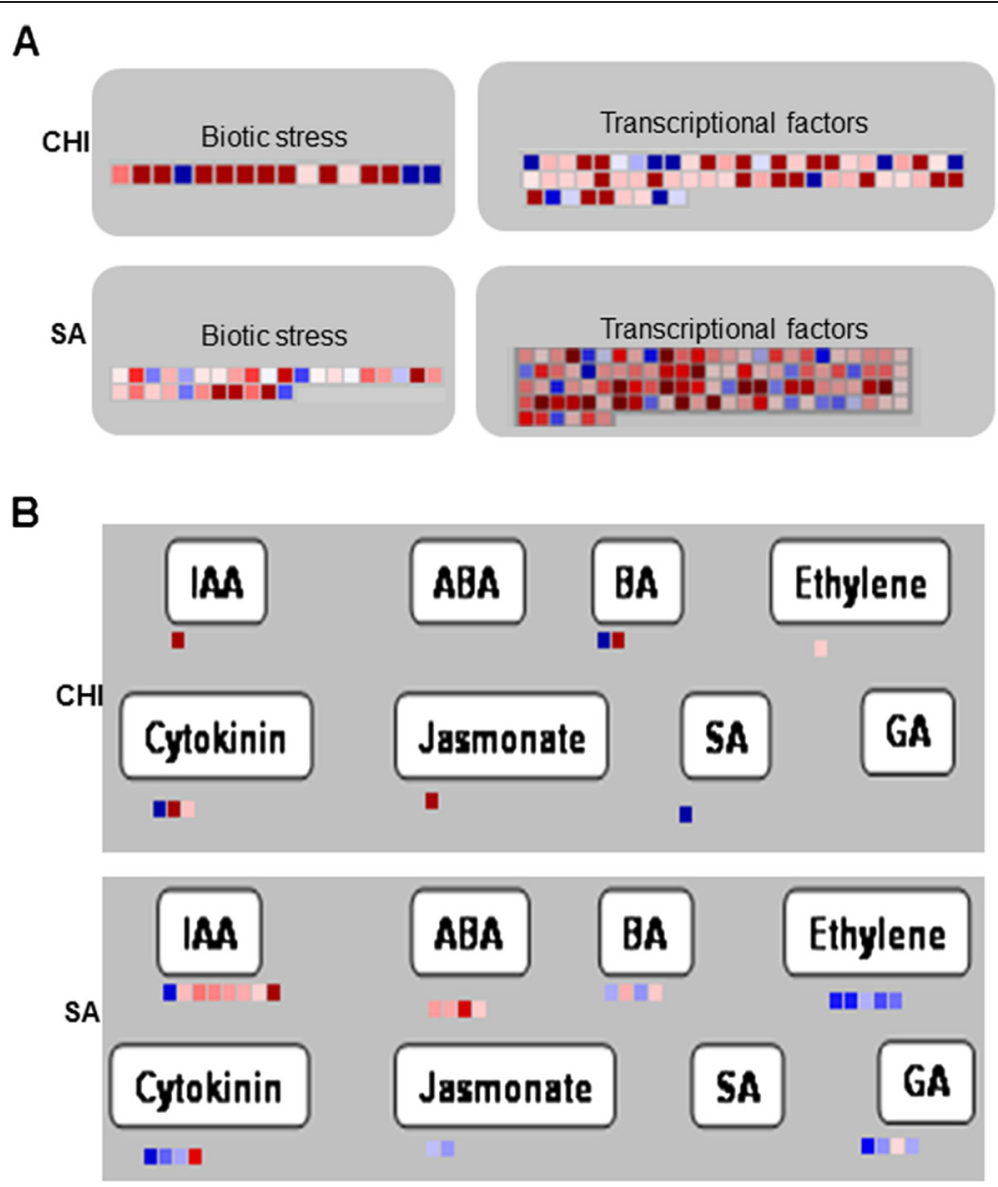

Figure 4 MapMan screenshots showing the expression of treatments-modulated genes. (A) Genes associated with biotic stress, abiotic stress and transcriptional factors, (B) differential expression of hormone-related transcripts in sweet orange submitted to SA and CHI treatments. The fold changes are indicated as gradients between red (down-regulated) and blue (up-regulated). Each point represents a transcript. IAA, indole-3-acetic acid; ABA, abscisic acid; BA,benzyladenine; SA, salicylic acid; GA, gibberellic acid.

and abiotic stress [51]. After an increase in the SA concentration in the cell cytosol, the WRKY family activates defense responses through its downstream components, which promote the expression of defense genes, such as the $P R$ genes [49]. The induction of WRKY genes by SA treatment or BTH treatment has been demonstrated in other plants [52-55].

For hormone metabolism, the most differentially represented transcripts in the profile of SA-treated plants were involved in the auxin pathway, and $87.5 \%$ of these were down-regulated (Figure 4B), including TIR1, $A R F 19$, and BIG transcriptional factors (Table 2). For CHI-treated plants, only nine genes were related to hormone metabolism, with most being down-regulated. We observed that the exogenous application of SA promoted an increase in the typical endogenous SA response because this hormone is able to attenuate auxin signaling, and reciprocally, the activation of the auxin pathway suppresses SA biosynthesis [56,57]. Genes involved in abscisic acid (ABA) biosynthesis and signaling were also repressed by SA treatment, such as ELD1, AREB3, and HVA22K (see Additional file 3: Table S3), which were not represented in the profile of CHItreated plants. The activation of this pathway promotes disease susceptibility to several pathogens, but this pathway is important for abiotic stress resistance [58,59]. The MapMan analyses showed no genes in the SA pathway, but closer analyses showed that several components of the SA pathway were identified, such as WRKY family members and SA-dependent $P R$ genes (Table 3 and Additional file 3: Table S3). A putative Sadenosylmethionine-dependent methyltransferase, which promotes the methylation of SA for the conversion into MeSA and is implicated in several aspects of plant defense signaling, was induced by $\mathrm{CHI}$ treatment (Table 4 and Additional file 3: Table S3).

Interestingly, genes involved in ET metabolism were up-regulated by SA treatment (Figure 4B), such as enzymes involved in synthesis and signal transduction (Table 3). In SA-treated plants, $15.6 \%$ of the up- 
regulated transcripts that were related to hormone metabolism were involved in ET metabolism, such as the ACS enzyme and AP2 domain-containing transcription factor (ERF105). Additionally, OPR3 (12-oxophytodienoate reductase 3 ) and proteinase inhibitors were up-regulated in SA-treated plants. The OPR3 enzyme is responsible for the conversion of JA from 12-oxophytodienoic acid, and proteinase inhibitors are produced by JA pathway signaling [60].

The hormone interactions that occur during the defense response in plants are complex, but it has been well demonstrated that SA and the auxin pathway interact antagonistically $[61,62]$. Similarly, ABA is able to antagonize the JA-ET signaling networks [62], and there have been data to suggest both positive and negative regulatory interactions between the ET and SA signaling pathways [63]. Our results showed that SA-treatment promotes an antagonism between SA and auxin and between SA and ABA because the repression of characteristic genes of the auxin and ABA pathways was observed. However, genes that participate in the SA pathway and the ET and JA biosynthesis pathways were induced, which is contrary to the idea that SA should suppress ET/JA synthesis. Several studies have suggested a mutual antagonism between SA and JA [64-68]. In contrast to this paradigm, some evidence has demonstrated strong positive interactions between the JA and SA pathways $[68,69]$. Sorghum treated with SA and other elicitors demonstrated the induction of genes belonging to the octadecanoic acid pathway of JA synthesis, and an increase in JA content was observed [22]. In tobacco and A. thaliana, there were indications that SA and JA act synergistically, suggesting that the two pathways regulate defense-related genes together $[68,69]$. We suggest that, in sweet orange, the three pathways (SA, ET, and JA) somehow interact early to promote an increase in the defense mechanism because we observed the induction of genes involved in ET and JA synthesis (ACS12 and OPR3, respectively) and in the SA pathway (WRKY, PR2, and PR9).

Our analysis demonstrated that the interaction among hormonal pathways promoted by exogenous SA occur together with cellular redox signaling because many hormones produce ROS [63]. A similar interaction has been described previously, and thioredoxins have been linked to the SA signaling cascade. During the SAR, the oligomeric cytosolic protein NPR1 forms monomers [70] to interact with nuclear TAG transcription factors, a process that requires thioredoxins [36]. For $\mathrm{CHI}$ treatment, we observed fewer transcriptional changes when compared to SA treatment.

\section{$P R$ genes}

Among the many components that are altered as a result of a plant's defensive response are the $P R$ genes, which may accumulate locally or systemically and are associated with the development of SAR. The induction of resistance may culminate with the expression of $P R$ genes, and both $\mathrm{CHI}$ and SA treatments have been demonstrated to induce these genes in other plants (Figure 3) [5,7,9,71-73]. The regulation of a number of genes encoding putative PR proteins was observed, such as trypsin and protease inhibitor/Kunitz family proteins, several disease resistance proteins (CC-NBS-LRR class), peroxidase (PR9) and glucanase (PR2), as well as a number of genes that were annotated as "pathogenesis-related" but not possessing homology to known PR genes (Additional file 3: Table S3 and Additional file 6: S5). Peroxidases and glucanases appeared to be induced by SA treatment, as assessed by RNA-seq and qRT-PCR (Table 3; Figure 2), but not by CHI treatment. The peroxidases are important for catalyzing lignin deposition in the cell wall, an important event in the primary defense against pathogens. Similarly, $\beta-1,3$-glucanase is a member of a family with antimicrobial properties [74]. Our results suggest that the expression of $P R$ genes following the application of SA may contribute to increased plant resistance against pathogens in sweet orange. Thus, additional studies are being conducted to evaluate the behavior of these genes in treated plants with SA and changelled with pathogens, and also to evaluate other plant tissue.

\section{Conclusions}

Using Illumina sequencing technology, we investigated the transcriptome of plants treated with $\mathrm{SA}$ and $\mathrm{CHI}$ and identified differentially expressed genes, with more genes being influenced by SA treatment than by $\mathrm{CHI}$ treatment. Analysis of the annotated genes showed significant increases in the expression levels of genes involved in signaling, biotic stress (redox state, secondary metabolism, $P R$ genes) and hormonal interaction, especially for SA treatment. SA treatment altered the expression of nearly twice the number of genes when compared to $\mathrm{CHI}$ treatment. We observed responses typical of endogenous SA, such as an increase in WRKY transcriptional factors (in this case, WRKY5O) and PR genes. Interestingly, our results did not show the suppression of ET/JA synthesis after the exogenous application of SA, but we did observe the suppression of the auxin pathway and the ABA pathway. Although $\mathrm{CHI}$ treatment promoted fewer changes in the transcriptional profile compared to SA treatment, it is possible that the elicitors promote the "priming phenomenon"; in this case, an increase in the capacity for the rapid and effective activation of defense mechanisms occurs only after contact with the pathogen, which involves $P R$ genes, an oxidative burst, cell wall lignification, and the secretion of phytoalexins [75]. Thus, we expanded the knowledge 
regarding defense induced by elicitors in a species of citrus that is susceptible to various diseases as well as the molecular mechanisms mediated by $\mathrm{SA} / \mathrm{CHI}$ treatments. Additional studies are being conducted to evaluate the effects of these compounds against citrus pathogens in leaves and other plant tissues.

\section{Methods}

\section{Plant materials and treatment with elicitors}

Seven-month-old sweet orange cv. Pera (Citrus sinensis) plants grafted onto Rangpur lime were selected from a uniform population and used in the experiment. SA (Sigma Aldrich Chemicals) was dissolved in 10\% ethanol and the $\mathrm{CHI}$ was prepared in $0.05 \mathrm{~N}$ hydrochloric acid, and the $\mathrm{pH}$ was adjusted to 5.6 with $\mathrm{NaOH}$ before use. The concentrations were determined in a preliminary experiment in which plants healthy were treated as follows: SA at concentrations of $0,1.25,2.5$ and $5 \mathrm{mM}$, and $\mathrm{CHI}$ 0, 1, 2 and $4 \mathrm{mg} / \mathrm{ml}$. Solutions of $10 \%$ ethanol (E) and $0.05 \mathrm{~N}$ hydrochloric acid (H), pH 5.6, were used as controls (mock) for SA and CHI, respectively. After 1, 12, 24 and 48 hours of spraying elicitors until point of running off the leaves, leaf samples were collected, immediately placed in liquid nitrogen and stored at $-80^{\circ} \mathrm{C}$ until extraction of RNA for analysis of expression of four genes related to resistance (NPR1-3 WRKY7O, PR1 and PR4) by qRT-PCR. These genes were selected because it is known that their orthologues participate in pathways regulated by SA or ethylene in Arabidopsis $[49,61]$.

After determine the best conditions (concentration and intervals) which promoted higher expression of these defense genes, was conduced the experiment to evaluate the transcriptome. Three plants were used for each treatment and were sprayed with the treatment solutions. Young leaf samples (two leaves per plant) from the three replicates were harvested $24 \mathrm{~h}$ post-treatment for $2.5 \mathrm{mM}$ $\mathrm{SA}$ and $48 \mathrm{~h}$ post-treatment for $4 \mathrm{mg} / \mathrm{mL} \mathrm{CHI}$, immediately frozen in liquid nitrogen, and stored at $-80^{\circ} \mathrm{C}$ for RNA extraction.

\section{RNA extraction and RNA-seq preparation}

Total RNA was extracted from $100 \mathrm{mg}$ of fresh tissue from each replicate with Tri Reagent (Life Technologies, Foster City, CA), according to the manufacturer's protocol. The total RNA was treated with RNase-free DNase (Qiagen, Maryland, USA), and then the replicates from each treatment were combined in a pool $(10 \mu \mathrm{g})$ according to Venturini et al. (2013) [76] and sent to Macrogen (South Korea) for mRNA purification, cDNA library construction and sequencing, using the Genome Analyzer IIx platform (Illumina/Solexa technology).

\section{Sequence analysis}

The raw data from the RNA-seq in Fasta format and with a quality score of Phred $\geq 20$ were indexed, trimmed, and aligned. The transcripts were mapped against the whole reference genome of Citrus clementina [77] by using TopHat software [78]. An initial consensus of the exon sequences was extracted from the mapped reads and was used to measure the relative abundance of transcripts, with Cufflink software [79]. A quantitative evaluation of the transcripts was used to calculate the levels of differential expression between the treatment and control groups and their levels of significance using Cuffdiff software [79]. These softwares are commonly used for differential expression analysis for RNA-seq samples [80]. The differentially expressed transcripts $(P \leq 0.05$ and $\geq 1$ fold change) were annotated and categorized automatically on GO (Gene Ontology - https://www.blast2go.com/). The functions of the identified genes were validated using BLASTx data from A. thaliana. PageMan [25] and MapMan 3.5.1R2 [26] softwares were used to visualize any functional classes that were significantly altered by the treatments.

To validate the mRNA abundance of 15 genes found to be significantly regulated by the compounds during the RNA-seq analysis, qRT-PCR was also performed. cDNAs were generated using the same RNA samples as those used for the RNA-seq experiment. For each sample, $1 \mu \mathrm{g}$ of total RNA was used with the RevertAid ${ }^{\mathrm{Tx}} \mathrm{H}$ Minus First Strand cDNA Synthesis Kit, according to the manufacturer's protocol (Fermentas, USA). The cDNA was diluted in RNase-free water $(1: 25)$ and stored at $-80^{\circ} \mathrm{C}$ until used for qRT-PCR analysis. The qRT-PCR assay was performed with three technical replicates using the Fast SYBR Green Master Mix (Life Tecnhologies, Foster City, CA) on an ABI 7500 Real Time PCR system in a total volume of $20 \mu \mathrm{L}$. The PCR cycle consisted of one $20 \mathrm{~s}$ cycle at $95^{\circ} \mathrm{C}$, followed by 40 cycles at $95^{\circ} \mathrm{C}$ for $3 \mathrm{~s}$ and $60^{\circ} \mathrm{C}$ for $30 \mathrm{~s}$. All amplified products were subjected to melt curve analysis. A negative control without a cDNA template was run with all analyses to evaluate the overall specificity. The reference genes ubiquitin and cyclophilin were used to normalize the total amount of cDNA in each reaction. These genes were the most stable, as was also reported by Rodrigues et al. [80]. Then, amplification efficiency and relative gene expression levels were calculated using Miner tool [81] and GenEx 4.3.5. To assess the correlation between different analyses, Pearson correlations were calculated using Bioestat 5.0 [82] to compare the gene expression levels measured by RNA-seq and qRT-PCR. To assess the significant differences between treatments, Student's t-test for independent samples was calculated using Bioestat 5.0. Gene-specific primers were designed using Primer premier 5.0 software and were synthesized by Exxtend (São Paulo, Brazil). Detailed information regarding the selected genes can be found in Additional file 9: Table S7. 


\section{Availability of supporting data}

The data sets supporting the results of this article are available in the NCBI Sequence Read Archive repository, Bioproject PRJNA261357 in http://www.ncbi.nlm.nih.gov/ bioproject/?term=PRJNA261357, SRR1581242, SRR1581243, SRR1581244, and SRR1581245.

\section{Additional files}

Additional file 1: Table S1. Differential expression analysis in SA-treated plants.

Additional file 2: Table S2. Differential expression analysis in $\mathrm{CHI}$-treated plants.

Additional file 3: Table S3. Biological processes altered by SA treatment. Additional file 4: Table S4-1. Differentially expressed genes that were upregulated in SA-treated plants.

Additional file 5: Table S4-2. Differentially expressed genes that were downregulated in SA-treated plants.

Additional file 6: Table S5. Biological processes altered by $\mathrm{CH}$ treatment. Additional file 7: Table S6-1. Differentially expressed genes that were upregulated in $\mathrm{CH}$-treated plants.

Additional file 8: Table S6-2. Differentially expressed genes that were downregulated in $\mathrm{CHI}$-treated plants.

Additional file 9: Table S7. Primers used for validation in qRT-PCR.

\section{Abbreviations}

SA: Salicylic acid; CHI: Chitosan; DEGs: Differentially expressed genes; QRT-PCR: Quantitative Real-Time PCR; IMP: Integrated management of plant; SAR: Systemic acquired resistance; PR: Pathogenesis-related; A1MV: Alfalfa mosaic virus; JA: Jasmonic acid; MeJA: Methyl jasmonate; 2OG: 2oxoglutarate; LRR: Leucine rich repeats; RLK: Receptor-like kinase; PLC: Phosphoinositide-specific phospholipase C; NO: Nitric oxide; ROS: Reactive oxygen species; BTH: Benzothiadiazole S-methylester; ET: Ethylene; ABA: Abscisic acid; GO: Gene Ontology.

\section{Competing interests}

The authors declare that they have no competing interests.

\section{Authors' contributions}

The following authors conceived and designed the experiments: DSOC, AAS, MAT, and MAM. The following author performed the experiments: DSOC. The following authors analyzed the data: DSOC, AAS, MAT, CMR, LTK, and MAM. The following author wrote the paper: DSOC. The following authors read, corrected and approved the final manuscript: DSOC, AAS, MAT, CMR, LTK, and MAM. All authors read and approved the final manuscript.

\section{Acknowledgments}

The present study was conducted with the financial support of Coordenação de Aperfeiçoamento de Pessoal de Nível Superior (CAPES), which provided a scholarship to DSOC and Instituto Nacional de Ciência e Tecnologia (INCT) de Genômica para Melhoramento de Citros (CNPq Process n. 573848/2008-4 and FAPESP Process n. 2008/57909-2). MAM, AAS, and MAT are CNPq fellows.

\section{Author details}

'Laboratório de Biotecnologia, Centro de Citricultura Sylvio Moreira, IAC, Cordeirópolis, São Paulo, Brasil. ${ }^{2}$ Universidade Federal da Bahia, UFBA, Vitória da Conquista, Bahia, Brasil. ${ }^{3}$ Universidade Federal de São Carlos, São Carlos, São Paulo, Brasil.

Received: 17 July 2014 Accepted: 6 March 2015

Published online: 12 April 2015

\section{References}

1. Food and Agricultural Organization of the United Nations. [http://Faostat.fao.org]
2. Mauch-Mani B, Métraux J. Salicylic acid and systemic acquired resistance to pathogen attack. Ann Bot. 1998;82:535-40.

3. Zhao J, Davis LC, Verpoorte RV. Elicitor signal transduction leading to production of plant secondary metabolites. Biotechnol Adv. 2005;23:283-333.

4. Raskin I. Role of salicylic acid in plants. Annu Rev Plant Physiol. 1992;43:439-63.

5. Hooft Van Huijsduijnen RAM, Alblas SW, de Rijk RH, Bolr JF. Induction by salicylic acid of pathogenesis-related proteins and resistance to alfalfa mosaic virus infection in various plant species. J Gen Virol. 1986;67:2135-43.

6. He CT, Wolyn DJ. Potential role for salicylic acid in induced resistance of asparagus roots to Fusarium oxysporum f. sp. asparagi. Plant Pathol. 2005;54:227-32.

7. Mandal S, Mallick N, Mitra A. Salicylic acid-induced resistance to Fusarium oxysporum f. sp. lycopersici in tomato. Plant Physiol Biochem. 2009;47:642-9.

8. Mandal S, Kar I, Mukherjee AK, Acharya P. Elicitor-induced defense responses in Solanum lycopersicum against Ralstonia solanacearum. Sci World J. 2013;2013:561056.

9. Babu RM, Sajeena A, VijayaSamundeeswari A, Sreedhar A, Vidhyasekaran P, Seetharaman $\mathrm{K}$, et al. Induction of systemic resistance to Xanthomonas oryzae pv. oryzae by salicylic acid in Oryza sativa (L.). J Plant Dis Prot. 2003;110:419-31

10. Renault A, Deloire A, Bierne J. Pathogenesis-related proteins in grapevines induced by salicylic acid and Botrytis cinerea. Vitis. 1996;35:49-52.

11. Palva TK, Hurtig M, Saindrenan P, Palva ET. Salicylic acid induced resistance to Erwinia carotovora subsp. Carotovora in tobacco. Mol Plant Microbe Interact. 1994;7:356-63.

12. Wang Y, Liu J. Exogenous treatment with salicylic acid attenuates occurrence of citrus canker in susceptible navel orange (Citrus sinensis Osbeck). J Plant Physiol. 2012;169:1143-9.

13. Faoro F, Maffi D, Cantu D, Iriti M. Chemical-induced resistance against powdery mildew in barley: the effects of chitosan and benzothiadiazole. Bio Control. 2008;53:387-401.

14. Iriti M, Faoro F. Abscisic acid mediates the chitosan-induced resistance in plant against viral disease. Plant Physiol Biochem. 2008;46:1106-11.

15. Cavalcanti FR, Resende MLV, Carvalho CPS, Silveira JAG, Oliveira JTA. An aqueous suspension of Crinipellis perniciosa mycelium activates tomato defence responses against Xanthomonas vesicatoria. Crop Prot. 2007;26:729-38.

16. Bautista-Baños S, Hernández-Lauzardo AN, Velázquez-Del Valle MG, Hernández-López MG, AitBarka E, Bosquez-Molina E, et al. Chitosan as a potential natural compound to control pre and postharvest diseases of horticultural commodities. Crop Prot. 2006;25:108-18.

17. Majeti NV, Kumar R. A review of chitin and chitosan applications. React Funct Poly. 2000;46:1-27.

18. Iriti M, Vitalini S, Di tommaso G, D'amico S, Borgo M, Faoro F. New chitosan formulation prevents grapevine powdery mildew infection and improves polyphenol content and free radical scavenging activity of grape and wine. Aust J Grape Wine Res. 2011;17:263-9.

19. Coqueiro DSO, Maraschin M, Di Piero RM. Chitosan reduces bacterial spot severity and acts in phenylpropanoid metabolism in tomato plants. J Phytopathol. 2011;159:488-94.

20. Romanazzi G, Nigro F, Ippolito A, Di Venere D, Saler DM. Effects of pre- and postharvest chitosan treatments to control storage grey mold of table grapes. J Food Sci. 2002;67:1862-7.

21. Rappussi MCC, Pascholati SF, Benato EA, Cia P. Chitosan reduces infection by Guignardia citricarpa in postharvest Valencia' oranges. Braz Arch Biol Technol. 2009:52:513-21.

22. Salzman RA, Brady JA, Finlayson SA, Buchanan CD, Summer EJ, SUN F, et al. Transcriptional profiling of sorghum induced by methyl jasmonate, salicylic acid, and aminocyclopropane carboxylic acid reveals cooperative regulation and novel gene responses. Plant Physiol. 2005;138:352-68.

23. Li ST, Zhang P, Zhang M, Fu CH, Zhao CF, Dong YS, et al. Transcriptional profile of Taxus chinensis cells in response to methyl jasmonate. BMC Genomics. 2012;13:295-305.

24. Povero G, Loreti E, Pucciariello CH, Santaniello A, Di Tommaso D, Tommaso GD, et al. Transcript profiling of chitosan-treated Arabidopsis seedlings. J Plant Res. 2011;124:619-29.

25. Usadel B, Nagel A, Steinhauser D, Gibon Y, Blasing OE, Redestig H, et al. PageMan: An interactive ontology tool to generate, display, and annotate overview graphs for profiling experiments. BMC Bioinformatics. 2006;7:535-42.

26. Thimm O, Bläsing $O$, Gibon $Y$, Nagel A, Meyer $S$, Krüger $P$, et al. MAPMAN: a user-driven tool to display genomics data sets onto diagrams of metabolic pathways and other biological processes. Plant J. 2004;37(6):914-39. 
27. Van Der Luit AH, Piatti T, Van Doorn A, Musgrave A, Felix G, Boller T, et al. Elicitation of suspension cultured tomato cells triggers the formation of phosphatidic acid and diacylglycerol pyrophosphate. Plant Physiol. 2000;123:1507-16.

28. Ohtake Y, Takahashi T, Komeda Y. Salicylic acid induces the expression of a number of receptor-like kinase genes in Arabidopsis thaliana. Plant Cell Physiol. 2000;41:1038-44.

29. Kaku H, Nishizawa Y, Ishii-Minami N, Akimoto-Tomiyama C, Dohmae N, Takio K, et al. Plant cells recognize chitin fragments for defense signaling through a plasma membrane receptor. Proc Nat Acad Sci. 2006;103:11086-91.

30. Mur LA, Sivakumaran A, Mandon J, Cristescu SM, Harren FJ, Hebelstrup KH. Haemoglobin modulates salicylate and jasmonate/ethylene mediated resistance mechanisms against pathogens. J Exp Bot. 2012;63:4375-87.

31. Zottini M, Costa A, De Michele R, Ruzzene M, Carimi F, Schiavo FL. Salicylic acid activates nitric oxide synthesis in Arabidopsis. J Exp Bot. 2007:58:1397-405.

32. Durner J, Klessig DF. Nitric oxide as a signal in plants. Curr Opin Plant Biol. 1999:2:369-74

33. Van Camp W, Montagu MV, Gent U, Inzé D. H2O2 and NO: redox signals in disease resistance. Trends Plant Sci. 1998;3:330-4.

34. Klessig DF, Durner J, Noad R, Navarre DA, Wendehenne D, Kumar D, et al. Nitric oxide and salicylic acid signaling in plant defense. Proc Nat Acad Sci. 2000;97:8849-55

35. Suzuki N, Koussevitzky S, Mittler R, Miller G. ROS and redox signalling in the response of plants to abiotic stress. Plant Cell Environ. 2012;35:259-70.

36. Tada Y, Spoel SH, Pajerowska-Mukhtar K, Mou Z, Song J. Plant immunity requires conformational changes [corrected] of NPR1 via S-nitrosylation and thioredoxins. Science. 2008:321:952-6.

37. Mittler R, Herr EH, Orvar BL, Van Camp W, Willekens H, Inze D, et al. Transgenic tobacco plants with reduced capability to detoxify reactive oxygen intermediates are hyperresponsive to pathogen infection. Proc Nat Acad Sci. 1999;96:14165-70.

38. Kliebenstein DJ, Dietrich RA, Martin AC, Last RL, Dang JL. LSD1 Regulates Salicylic Acid Induction of Copper Zinc Superoxide Dismutase in Arabidopsis thaliana. Mol Plant Microbe Interact. 1999;12:1022-6.

39. Li H, Yu T. Effect of chitosan on incidence of brown rot, quality and physiological attributes of postharvest peach fruit. J Sci Food Agric. 2000;81:269-74.

40. McQueen-Mason S, Durachko DM, Cosgrove DJ. Two endogenous proteins that induce cell wall extension in plants. Plant Cell. 1992;4:1425-33.

41. Ding $X$, Cao Y, Huang L, Zhao J, Xu C, Li X, et al. Activation of the indole-3acetic acid-amidosynthetase $\mathrm{GH} 3-8$ suppresses expansin expression and promotes salicylate- and jasmonate-independent basal immunity in rice. Plant Cell. 2008:20:228-40.

42. Navarro L, Dunoyer P, Jay F, Arnold B, Dharmasiri N, Estelle M, et al. A Plant miRNA contributes to antibacterial resistance by repressing auxin signaling. Science. 2006;312:436-9.

43. Wang D, Pajerowska-Mukhtar K, Culler AH, Dong X. Salicylic acid inhibits pathogen growth in plants through repression of the auxin signaling pathway. Curr Biol. 2007:17:1784-90.

44. Aravind L, Koonin EV. The DNA-repair protein AlkB, EGL-9, and leprecan define new families of 2-oxoglutarate- and iron dependent dioxygenases. Genome Biol. 2001;2:0007.1-8.

45. Van Damme M, Huibers RP, Elberse J, Van Den Ackerveken G. Arabidopsis DMR6 encodes a putative 2OG-Fe(II) oxygenase that is defense-associated but required for susceptibility to downy mildew. Plant J. 2008:54:785-93.

46. De Moraes CM, Mescheer MC, Tumlinson JH. Caterpillar-induced nocturnal plant volatiles repel nonspecific females. Nature. 2001;410:577-80.

47. Kessler A, Baldwin IT. Defensive function of herbivore-induced plant volatile emissions in nature. Science. 2001;291:2141-4.

48. Andersen RA, Hamilton-Kemp TR, Hildebrand DF, McCracken Jr CT, Collins RW, Fleming PD. Structure-antifungal activity relationships among volatile $C_{6}$ and $C_{9}$ aliphatic aldehydes, ketones and alcohols. J Agric Food Chem. 1994;42:1563-8.

49. Vlot AC, Dempsey DMA, Klessig DF. Salicylic Acid, a multifaceted hormone to combat disease. Annu Rev Phytopathol. 2009:47:177-206.

50. Eulgem T, Rushton PJ, Robatzek S, Somssich IE. The WRKY superfamily of plant transcription factors. Trends Plant Sci. 2000;5:199-205.

51. Chujo T, Kato T, Yamada K, Takai R, Akimoto-Tomiyama C, Minami E, et al. Characterization of an elicitor-induced rice WRKY gene, OsWRKY71. Biosci Biotechnol Biochem. 2008;72:240-5.

52. Liu $X$, Bai $X$, Wang $X$, Chu C. OsWRKY71, a rice transcription factor, is involved in rice defense response. J Plant Physiol. 2007;164:969-79.
53. Shimono M, Sugano S, Nakayama A, Jiang CJ, Ono K, Toki S, et al. Rice WRKY45 plays a crucial role in benzothiadiazole-inducible blast resistance. Plant Cell. 2007;19:2064-76

54. Dong J, Chen C, Chen Z. Expression profiles of the Arabidopsis WRKY gene superfamily during plant defense response. Plant Mol Biol. 2003;51:21-37.

55. Levée V, Major I, Levasseur C, Tremblay L, Mackay J, Séguim A. Expression profiling and functional analysis of PopulusWRKY23 reveals a regulatory role in defense. New Phytol. 2009;184:48-70.

56. Robert-Seilaniantz A, Navarro L, Bari R, Jones JD. Pathological hormone imbalances. Curr Opin Plant Biol. 2007;10:372-9.

57. Asselbergh B, Curvers K, Franca SC, Audenaert K, Vuylsteke M, Breusegem V, et al. Resistance to Botrytis cinerea in sitiens, an abscisic acid-deficient tomato mutant, involves timely production of hydrogen peroxide and cell wall modifications in the epidermis. Plant Physiol. 2007:44:1863-77.

58. Nambara E, Marion-Poll A. Abscisic acid biosynthesis and catabolism. Annu Rev Plant Biol. 2005;56:165-85.

59. Creelman RA, Mullet JE. Jasmonic acid distribution and action in plants: Regulation during development and response to biotic and abiotic stress. Proc Natl Acad Sci. 1995;92:4114-9.

60. Navarro L, Bari R, Achard P, Lison P, Nemri A, Harberd NP, et al. DELLAs control plant immune responses by modulating the balance of jasmonic acid and salicylic acid signaling. Curr Bio. 2008;118:650-5.

61. Anderson JP, Badruzsaufari E, Schenk PM, Manners JM, Desmond OJ, Ehlert C, et al. Antagonistic interaction between abscisic acid and jasmonate-ethylene signaling pathways modulates defense gene expression and disease resistance in Arabidopsis. Plant Cell. 2004;16:3460-79.

62. Doherty HM, Selvendran RR, Bowles DJ. The wound response of tomato plants can be inhibited by aspirin and related hydroxybenzoic acids. Physiol Mol Plant Pathol. 1988:33:377-84.

63. Bartoli CG, Casalongue CA, Simontacchi M, Marquez-Garcia B, Foyer CH. Interactions between hormone and redox signalling pathways in the control of growth and cross tolerance to stress. Environ Exp 2012, Botdoi.org/10.1016/j.envexpbot.2012.05.003.

64. Pena-Cortes H, Albrecht T, Prat S, Weiler EW, Willmitzer L. Aspirin prevents wound-induced gene expression in tomato leaves by blocking jasmonic acid biosynthesis. Planta. 1993;191:123-8.

65. Doares SH, Narvaez-Vasquez J, Conconin A, Ryan CA. Salicylic acid inhibits synthesis of proteinase inhibitors in tomato leaves induced by systemin and jasmonic acid. Plant Physiol. 1995;108:1741-6.

66. Gupta V, Willits MG, Glazebrook J. Arabidopsis thaliana EDS4 contributes to salicylic acid (SA)-dependent expression of defense responses: evidence for inhibition of jasmonic acid signaling by SA. Mol Plant Microbe Interact. 2000;13:503-11.

67. Niki T, Mitsuhara I, Seo S, Ohtsubo N, Ohashi Y. Antagonistic effect of salicylic acid and jasmonic acid on the expression of pathogenesis-related (PR) protein genes in wounded mature tobacco leaves. Plant Cell Physiol. 1998;39:500-7.

68. Schenk PM, Kazan K, Wilson I, Anderson JP, Richmond T. Coordinated plant defense responses in Arabidopsis revealed by microarray analysis. Proc Natl Acad Sci. 2000:97:11655-60.

69. Xu Y, Chang PLC, Liu D, Narasimhan ML, Kashchandra GR. Plant defense genes are synergistically induced by ethylene and methyl jasmonate. Plant Cell. 1994;6:1077-85.

70. Després C, Chubak C, Rochon A, Clark R, Bethune T. The Arabidopsis NPR1 disease resistance protein is a novel cofactor that confers redox regulation of DNA binding activity. Plant Cell. 2003;15:2181-91.

71. Falcón-Rodríguez AB, Costales D, Cabrera JC, Martínez-Téllez MA. Chitosan physico-chemical properties modulate defense responses and resistance in tobacco plants against the oomycete Phytophthor anicotianae. Pest Biochem Physiol 2011, doi:10.1016/j.pestbp.2011.04.005.

72. Reglinskia T, Elmera PAG, Taylora JT, Woodb PN, Hoyte SM. Inhibition of Botrytis cinerea growth and suppression of botrytis bunch rot in grapes using chitosan. Plant Pathol. 2010;59:882-90.

73. Yalpani N, Shulaev V, Raskin I. Endogenous salicylic acid levels correlate with accumulation of pathogenesis-related proteins and virus resistance in tabacco. Phytopathology. 1993;83:702-8.

74. Van Loon LC, Rep M, Pieterse CMJ. Significance of inducible defense-related proteins in infected plants. Annu Rev Phytopathol. 2006;44:135-62.

75. Conrath U, Pieterse CM, Mauch-Mani B. Priming in plant-pathogen interactions. Trends Plant Sci. 2002;7:210-6. 
76. Venturini L, Ferrarini A, Zenoni S, Tornielli GB, Fasoli M, Santo SD, et al. De novo transcriptome characterization of Vitis vinifera cv. Corvina unveils varietal diversity. BMC Genomics. 2013;14:41.

77. Wu GA, Prochnik S, Jenkins J, Salse J, Hellsten U, Murat F, et al. Sequencing of diverse mandarin, pummelo and orange genomes reveals complex history of admixture during citrus domestication. Nat Biotechnol. 2014;32:656-62.

78. Trapnell C, Pachter L, Salzberg SL. TopHat: discovering splice junctions with RNA-seq. Bioinformatics. 2009;25:1105-11.

79. Trapnell C, Williams BA, Pertea G, Mortazavi A, Kwan G, Van Baren MJ, et al. Transcript assembly and quantification by RNA-Seq reveals unannotated transcripts and isoform switching during cell differentiation. Nat Biotechnol. 2010;28:511-5.

80. Rodrigues CM, De Souza AA, Takita MA, Kishi LT, Machado MA. RNA-Seq analysis of Citrus reticulata in the early stages of Xylella fastidiosa infection reveals auxin-related genes as a defense response. BMC Genomics. 2013;14:676.

81. Zhao S, Fernald RD. Comprehensive algorithm for quantitative real-time polymerase chain reaction. J Comput Biol. 2005;12:1045-62.

82. Ayres M, Ayres Júnior M, Ayres DL, Santos AA. Bioestat: aplicações estatísticas nas áreas das ciências bio-médicas. Belém: ONG Mamiraua; 2007.

\section{Submit your next manuscript to BioMed Central and take full advantage of:}

- Convenient online submission

- Thorough peer review

- No space constraints or color figure charges

- Immediate publication on acceptance

- Inclusion in PubMed, CAS, Scopus and Google Scholar

- Research which is freely available for redistribution 